\title{
Structural Behavior and Design of Barrier-Overhang Connection in Concrete Bridge Superstructures Using AASHTO LRFD Method
}

\author{
Byungik Chang, ${ }^{1}$ Kamal Mirtalaei, ${ }^{2}$ Seungyeol Lee, ${ }^{3}$ and Kenneth Leitch ${ }^{1}$ \\ ${ }^{1}$ Department of Engineering and Computer Science, West Texas A\&M University, 2403 Russell Long Boulevard, WTAMU Box 60767, \\ Canyon, TX 79016, USA \\ ${ }^{2}$ Engineering Technical Group, Arizona Department of Transportation, 205 South 17th Avenue, MD 618E, Phoenix, AZ 85007, USA \\ ${ }^{3}$ Nfra Inc., 77 E. Thomas Road, Suite 200, Phoenix, AZ 85012, USA \\ Correspondence should be addressed to Byungik Chang, bchang@wtamu.edu
}

Received 9 January 2012; Revised 25 April 2012; Accepted 1 May 2012

Academic Editor: Sami W. Tabsh

Copyright () 2012 Byungik Chang et al. This is an open access article distributed under the Creative Commons Attribution License, which permits unrestricted use, distribution, and reproduction in any medium, provided the original work is properly cited.

\begin{abstract}
The U.S. Departments of Transportation adopted the AASHTO LRFD Bridge Design Specifications during the year 2007, which is mandated by AASHTO and FHWA. The application of LRFD specification initiated numerous research works in this field. This investigation addresses the LRFD and Standard design methodologies of concrete deck slab, deck overhang, barrier and combined barrier-bridge overhang. The purpose of this study is to propose a simplified manual design approach for the barrier-deck overhang in concrete bridges. For concrete deck slab overhang and barrier, application of National Cooperative Highway Research Program crash test is reviewed. The failure mechanism, design philosophy and load cases including extreme event limit states for barrier and overhang are discussed. The overhang design for the combined effect of bending moment and axial tension is probably the most important part of the design process. The overhang might be a critical design point of the deck with significantly higher amount of reinforcement. The design process becomes complicated due to combined force effect, LRFD crash test level requirement and the existence of several load combinations. Using this program, different LRFD load combinations are plotted together with the interaction diagram and the design is validated.
\end{abstract}

\section{Introduction and Background}

For several years American Association of State Highway and Transportation Officials (AASHTO) standard specification [1] has been the main well-recognized bridge design tool in the United States. During the past 25 years, there have been significant developments in the concrete bridge design methods as well as utilization of new concrete materials. Many of the U.S. Departments of Transportation (USDOT) have already started the implementation of the AASHTO Load and Resistance Factor Design (LRFD) Bridge Design Specification [2]. The LRFD is based on the latest developments in structural analysis and materials to assure desired serviceability and ultimate behavior, safety, aesthetics, and economy. It benefits the valuable experiences of the AASHTO Allowable Stress Design (ASD) and Load Factor Design (LFD) methods, which have been in use for more than 70 years.
These changes resulted in design procedures significantly different compared to the earlier methods. The new LRFD specification has been calibrated to produce design results not very different with AASHTO standard specification [3]. The changes in the new LRFD design methods are significant and challenge the bridge engineers working with standard specification for so many years.

For federal funded highway projects, the USDOT have to adopt and implement the LRFD Bridge Design Specifications in 2007, which is mandated by AASHTO and Federal Highway Administration (FHWA). The task preparation of such enormous undertaking has initiated a number of research investigations of different aspects of the LRFD Specifications.

In the present work, a detailed investigation was performed to compare the difference between the Standard and the LRFD methods for interior concrete deck slab design. The purpose of this study is to propose a simplified 
manual design approach for the barrier-deck overhang in concrete bridges. For the barrier and deck overhang design, a new philosophy based on yield line theory and the actual behavior in a real crash test has been used by the AASHTO LRFD specification [2]. This methodology is significantly different and more complicated comparing to the conventional methods.

\section{Interior Deck Panels}

A computer program (spreadsheet) was developed for interior deck panel design. The current AASHTO LRFD Bridge Design specification introduces three different deck slab design methods for its analysis. LRFD traditional methods, which are Approximate methods (LRFD Article 4.6.2) or refined methods (LRFD Article 4.6.3), and LRFD empirical design methods for concrete slabs (LRFD Article 9.7.2) are the examples [2]. The approximate method is considered acceptable for decks other than fully filled and partially filled grids, which refer to concrete slab on the top of girder, partially embedding the girder or fully embedding the girders. The refined method is typically used in modeling with finite element analysis that would affect the accuracy of the analytical solution. Empirical design method is for concrete deck slabs supported by longitudinal components and applied not to overhangs but only to the primary slab.

The LRFD traditional method using approximate methods or the refined methods is based on an elastic analysis for which the design moments have been tabulated in the specification. An LRFD empirical method is also recommended with a limitation, which is the girder spacing that must be less than $4 \mathrm{~m}(13 \mathrm{ft})$. The deck slab reinforcement given by the empirical method is a value which is dependent neither on the girder/web spacing nor on the applied dead and live load. The amount of deck reinforcement given by this method is significantly less than those given by the LRFD traditional method or Standard LFD methods, and Figure 1 compares the deck reinforcement designed by three methods.

As shown in the figure, the required amount of reinforcement is dependent on girder spacing for LFD and LRFD traditional methods while the amount of reinforcement for LRFD empirical method is constant. By adopting the empirical design method for 2.74-m (9-ft) girder spacing, the required deck steel reinforcement is about $75 \%$ and $50 \%$ of those given by LFD and LRFD traditional methods, respectively. Because of the significant difference, most of the designers probably hesitate to use the LRFD empirical method.

\section{Concrete Barrier Design}

A federal standard, National Cooperative Highway Research Program (NCHRP) Report 350 [4], for the safety performance evaluation of highway features has been published, and extensive experimental investigation [5-8] for the study of barrier behavior has been conducted based on the standard. The NCHRP Report covered crash tests including proposed six test levels for the bridge railing design. Based

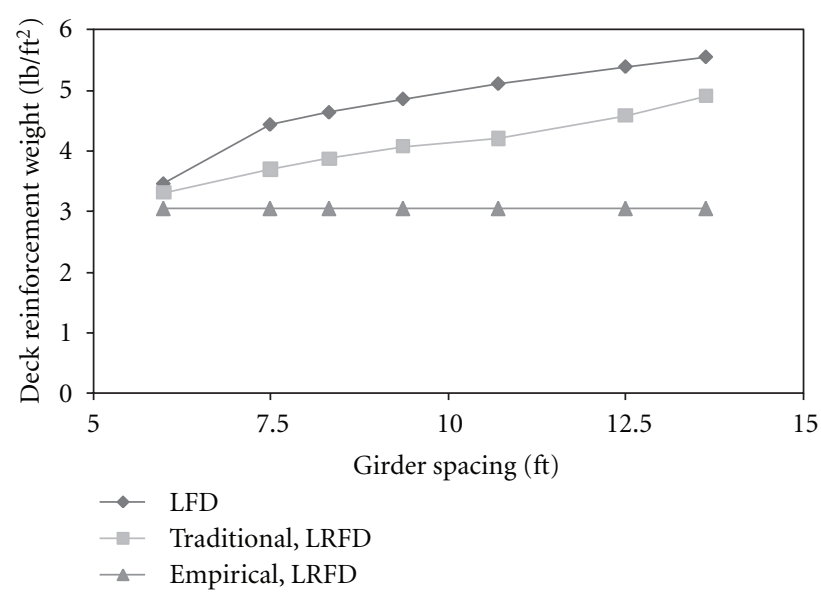

Figure 1: Comparison of deck reinforcement designed with different methods.

on the report, the LRFD specifies new bridge railing and concrete barrier performance level with respect to dynamic impact loads, vehicle speed, and others.

Table 1 [2] shows the minimum required design forces and dimension for traffic railing in current AASHTO LRFD Specification. In this table, the design transverse load $\left(F_{t}\right)$, longitudinal load $\left(F_{L}\right)$, vertical load $\left(F_{v}\right)$, and other geometrical design parameters $\left(L_{t}, L_{L}, L_{v}, H_{e}\right.$, and minimum height of rail) are given. With selecting the required crash test level, the overall barrier dimension and reinforcement will be designed using the parameters in the table. This would involve some iterative process because the magnitude and distribution of collision force depends on design capacity of the barrier.

\section{Design Procedure for Concrete Railing}

Yield line analysis and strength design for reinforced concrete barrier are typically used [2], and the nominal railing resistance to transverse load, $R_{w}$, can be determined using the yield line approach as shown (1) for impact within a wall (barrier) segment and for impact at end of wall (barrier) or joint, respectively. One has

$$
\begin{gathered}
R_{w}=\left(\frac{2}{2 L_{c}-L_{t}}\right) \cdot\left(8 M_{b}+8 M_{w} \cdot H+\frac{M_{c} \cdot L_{c}^{2}}{H}\right), \\
R_{w}=\left(\frac{2}{2 L_{c}-L_{t}}\right) \cdot\left(M_{b}+M_{w} \cdot H+\frac{M_{c} \cdot L_{c}^{2}}{H}\right),
\end{gathered}
$$

where $R_{w}$ is total transverse resistance of the barrier (kip), $L_{c}$ is critical length of yield line pattern $(\mathrm{ft})=L_{t} / 2+$ $\sqrt{\left(L_{t} / 2\right)^{2}+8 \cdot H \cdot\left(M_{b}+M_{w} \cdot H\right) / M_{c}}$ for impact within a wall segment $=L_{t} / 2+\sqrt{\left(L_{t} / 2\right)^{2}+H \cdot\left(M_{b}+M_{w} \cdot H / M_{c}\right)}$ for impact at end of wall or at joints, $L_{t}$ is longitudinal distribution length ( $\mathrm{ft}$ ), $M_{b}$ is additional flexural resistance (in addition to $M_{w}$, if any), not applicable here, $M_{w}$ is flexural 
TABLE 1: Minimum required design forces and dimension for traffic railing $(1 \mathrm{kip}=4.45 \mathrm{kN}, 1 \mathrm{ft}=0.31 \mathrm{~m})$.

\begin{tabular}{|c|c|c|c|c|c|c|c|}
\hline \multirow{2}{*}{ Design forces and designations } & \multicolumn{7}{|c|}{ Railing test levels } \\
\hline & TL-1 & TL-2 & TL-3 & TL-4 & TL-5A & TL-5 & TL-6 \\
\hline$F_{t}$ transverse (kip) & 13.5 & 27.0 & 54.0 & 54.0 & 116.0 & 124.0 & 175.0 \\
\hline$F_{L}$ longitudinal (kip) & 4.5 & 9.0 & 18.0 & 18.0 & 39.0 & 41.0 & 58.0 \\
\hline$F_{v}$ vertical (kip) down & 4.5 & 4.5 & 4.5 & 18.0 & 50.0 & 80.0 & 80.0 \\
\hline$L_{t}$ and $L_{L}(\mathrm{ft})$ & 4.0 & 4.0 & 4.0 & 3.5 & 8.0 & 8.0 & 8.0 \\
\hline$L_{v}(\mathrm{ft})$ & 18.0 & 18.0 & 18.0 & 18.0 & 40.0 & 40.0 & 40.0 \\
\hline$H_{e}(\min )($ in. $)$ & 18.0 & 20.0 & 24.0 & 32.0 & 40.0 & 42.0 & 56.0 \\
\hline Min. $H$ height of rail (in.) & 27.0 & 27.0 & 27.0 & 32.0 & 40.0 & 54.0 & 90.0 \\
\hline
\end{tabular}

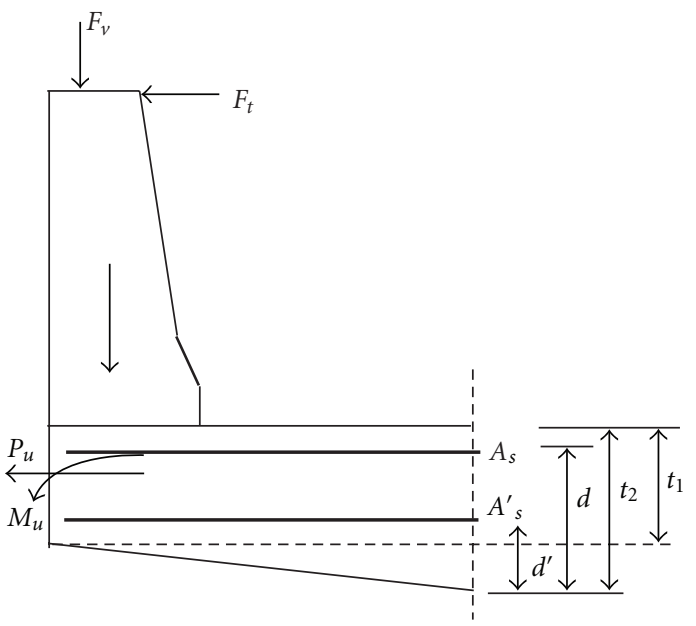

FIGURE 2: Deck overhang forces and dimensions.

resistance of the barrier about its vertical axis $(\mathrm{k}-\mathrm{ft} / \mathrm{ft}), M_{c}$ is flexural resistance of the barrier about its longitudinal axis (kip-ft/ft), and $H$ is barrier height (ft).

\section{Deck Overhang Behavior}

LRFD specification requires that deck overhang should have sufficient strength to withstand the loads received from a vehicle crash to barrier and resistance to force the yield line failure pattern to remain within the barrier. Figure 2 shows the transverse and vertical loads $\left(F_{v}\right.$ and $\left.F_{t}\right)$ applied to the top of barrier in a crash event.

It is suggested by AASHTO LRFD specification that the concrete deck overhang should not fail in a crash event before barrier. This means that overhang also should be capable to resist the reaction forces received from the barrier during a crash [2]. The extreme event tensile force, $P_{u}$ in (2), and flexural bending moment per linear foot, $M_{u}$ in (3), of the deck at the barrier-overhang connection will be as follows:

$$
\begin{gathered}
P_{u}=\frac{R_{W}}{L_{c}+2 H}, \\
M_{u}=\frac{R_{W} \cdot H}{L_{c}+2 H},
\end{gathered}
$$

where $R_{w}$ is total transverse resistance of the barrier (kip), $L_{c}$ is critical length of yield line pattern $(\mathrm{ft})$, and $H$ is barrier height (ft).

The deck overhangs should be designed in accordance with AASHTO LRFD Section 13 (Appendix A, Article A13.4), for the following design cases considered separately.

Design Case 1. This combination is Extreme Event II which includes transverse force $\left(F_{t}\right)$, longitudinal force $\left(F_{L}\right)$, and other dead loads. The distributed (per foot) transverse design tensile force and its associated bending moment are $P_{u}$ and $M_{u}$ as calculated by (2) and (3).

Design Case 2. This combination is Extreme Event II which includes vertical force $\left(F_{v}\right)$ and other dead loads.

Design Case 3. This combination is Strength I with the application of dead loads and normal vehicular live load. One wheel load will be placed at $30.5 \mathrm{~cm}(1 \mathrm{ft})$ from the face of barrier to calculate the distributed (per foot) bending moment in the overhang. An alternative equivalent continuous live load of $1 \mathrm{k} / \mathrm{ft}$ placed at $1 \mathrm{ft}(30.5 \mathrm{~cm})$ from the interior face of barrier is suggested by LRFD 3.6.1.3.4.

Note that Design Cases 1 and 2 may be considered either for continuous or joint locations at the barrier-overhang connection. Also dead load factor for Cases 1 and 2 may be assumed to be 1.0 according to LRFD Specification. Figures 3 and 4 show the bending moments along the overhang for all applicable load combinations.

\section{Load Combination Comparison}

The overhang length assumed to vary from 0.76 to $2.44 \mathrm{~m}$ $(2.5$ to $8 \mathrm{ft}$ ) in Figures 3 and 4 . As it is seen, the magnitude of bending moment for Extreme Event II, with $F_{v}$ application and Service I, is proportionally dependent on the overhang length. This means that by increasing the overhang length, the bending moment produced by $F_{v}$ or wheel load will proportionally increase. On the other hand, for Extreme Event II, with $F_{t}$ (which produces $P_{u}$ and $M_{u}$ ), moment is almost unchanged along the overhang (except that for the effect of dead loads which is insignificant). The reason is that in these combinations a large portion of the moment on the entire length of overhang is the crash bending reaction 


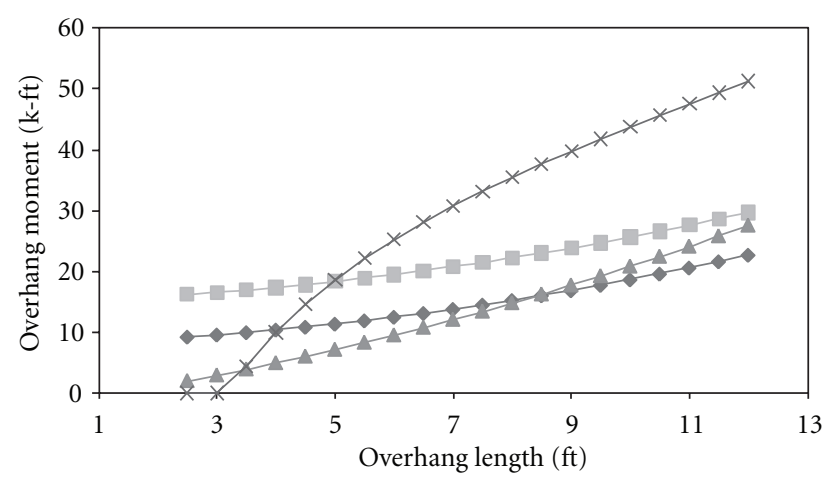

- Ext. eve. II, ft, continuous $\quad \rightarrow \quad$ Ext. eve. II, fv

$\neg$ Ext. eve. II, ft, at joint $\quad$ * Strength I

Figure 3: Overhang design moments for TL-4 and 32 in. barrier. Note: load combinations are the same as described in Section 6.

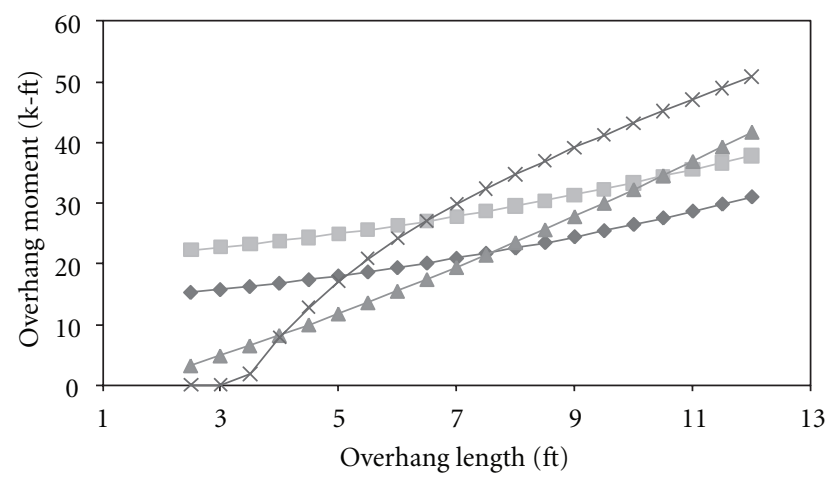

- Ext. eve. II, ft, continuous $\quad \succ \quad$ Ext. eve. II, fv

- Ext. eve. II, ft, at joint $\quad * \quad$ Strength I

Figure 4: Overhang design moments for TL-5 and 42 in. barrier. Note: load combinations are the same as described in Section 6.

received from the barrier. In other words, for Extreme Event II, only two forces are considered at the tip of overhang: a tensile force $\left(P_{u}\right)$ and a moment $\left(M_{u}\right)$. The effect of $P_{u}$ and $M_{u}$ will be constant along the whole length of overhang. It is seen in Figures 3 and 4 that extreme event II load combinations are almost constant and governing the design up to an overhang length of about 1.52 to $1.98 \mathrm{~m}$ ( 5 to $6.5 \mathrm{ft}$ ) (which might be the maximum practical length).

For a constant force effect along the overhang length, a variable overhang thickness cannot optimize the design. If a variable thickness is used, the minimum thickness (at the tip of overhang) will govern the design. Traditionally, designers consider a variable (haunch shaped) section for the overhang with minimum thickness at its tip. It is very interesting that a variable (haunch) overhang section cannot optimize the design for Extreme Event II load combinations. Table 2 shows the axial tension and associated moment for a $1.52 \mathrm{~m}$ ( $5 \mathrm{ft})$ overhang over I girders with $81.3 \mathrm{~cm}$ (32 in.) barrier using AASHTO LRFD test level 4 (TL-4).
TABLE 2: Load combinations for a 5 -ft overhang over I Girders and $\mathrm{TL}-4$ crash loads $(1 \mathrm{kip}=4.45 \mathrm{kN}, 1 \mathrm{ft}=0.31 \mathrm{~m})$.

\begin{tabular}{lcc}
\hline Load combination & $\begin{array}{c}\text { Tensile force, } P_{u} \\
\text { kip (per foot) }\end{array}$ & $\begin{array}{c}\text { Bending moment, } M_{u} \\
\text { k-ft (per foot) }\end{array}$ \\
\hline $\begin{array}{l}\text { Extreme Event II, } F_{t}, \\
\text { continuous }\end{array}$ & 3.2 & 11.1 \\
$\begin{array}{l}\text { Extreme Event II, } F_{t}, \\
\text { joint }\end{array}$ & 5.2 & 18.1 \\
$\begin{array}{l}\text { Extreme Event II, } F_{v}, \\
\text { continuous } \\
\text { Strength I }\end{array}$ & 0 & 8 \\
\hline
\end{tabular}

\section{Axial Tension-Bending Moment Interaction}

The first two load combinations in Table 2 require a design process for the rectangular concrete section under combined effect of axial force (tension) and bending moment. The manual application of classical column analysis will be time consuming and tedious. Furthermore, most of the existing column design charts are good only for axial compression which does not include the tensile portion of the column interaction curve.

It was decided in this investigation to develop a computer program in a "Spreadsheet Form" to perform this process. The program takes the initial information such as supporting elements (beams) width, overhang length and thickness (min and max in haunch shape), and material properties. The program then establishes all the load combinations (as in Table 2). It then initiates an approximate design based only on the maximum bending moment among all four load combinations (and ignoring the axial tension) to calculate the required amount of top reinforcements $\left(A_{s}\right.$ in Figure 2). The bottom bars $\left(A_{s}^{\prime}\right)$ are assumed to be similar (the continuation) to bottom bars designed for the interior panels within the same program. In the next step, a detailed section analysis is performed to construct the axial force-bending moment interaction diagram. This involves the assumptions for all possible failure modes (tensile, compression, and balance modes) to establish the failure surface. The analysis was extended for negative (tensile) axial force which is required for an overhang design.

\section{Overhang Design}

The calculated design combination forces (as in Table 2) are for unit width of overhang. The overhang length and material properties are also given. The program calculates the required area of top bars based only on the maximum bending from those four combinations. For initial approximation, the effect of tensile force is ignored. The overhang bottom bars are assumed to be the continuation of interior deck panel reinforcement. The interaction diagram (failure surface) can be constructed for the section. Each load combination can be plotted as a point on the same interaction diagram. The design is acceptable if all four points are inside the curve, otherwise either the slab thickness 


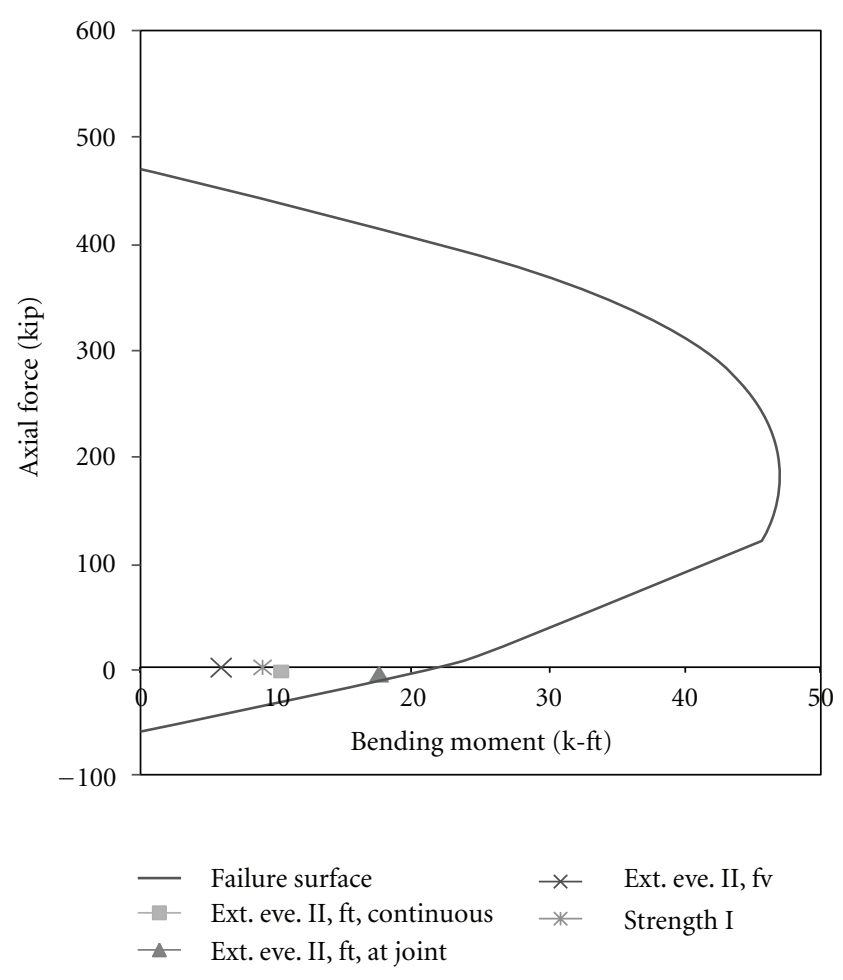

Figure 5: Generated interaction diagram for deck overhang.

or deck reinforcement should be revised to locate the loading points inside the curve. It should be noted that only the negative portion of diagram will be used for overhang design. Note that Load factors are according to AASHTO LRFD extreme event combination and a strength reduction factor of 0.9 applied to moments for design of steel reinforcement.

Figure 5 shows the interaction diagram with load combination plot points for a concrete overhang on AASHTO Type IV prestressed I-Girders with the following information:

Design Input. The design input includes the following:

girder spacing $=2.44 \mathrm{~m}(8 \mathrm{ft})$,

interior deck thickness $=20 \mathrm{~cm}(8 \mathrm{in}$.),

overhang length from CL of girders $=2.22 \mathrm{~m}(4 \mathrm{ft})$,

test level $=$ TL-4,

barrier size $=81.3 \mathrm{~cm}(32 \mathrm{in}$.),

min. overhang thickness, $t_{1}=8 \mathrm{in}$, and

max. overhang thickness, $t_{2}=30.5 \mathrm{~cm}$ (12 in.) (haunch).

Design Output (first run). The design output includes the following:

overhang top transverse bars (No.5@6 in.),

overhang bottom transverse bars (No.5@12 in.),

interior panel top transverse bars (No.5@10.3 in.),

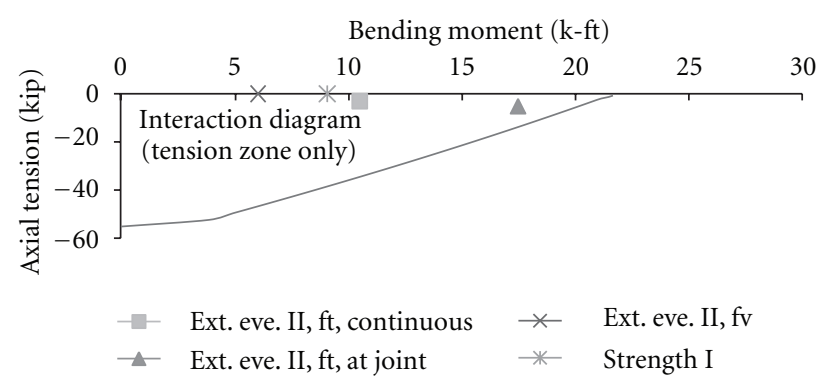

FIGURE 6: Interaction diagram for deck overhang (magnified tension part of the curve).

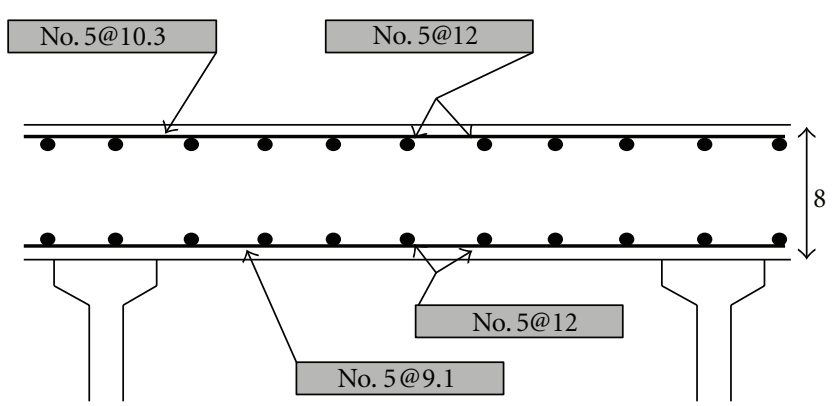

FIGURE 7: Interior deck panel LRFD design output for a girder-slab bridge (unit in inch).

interior panel top transverse bars (No.5@10.3 in.), and

interior panel bottom transverse bars (No. 5@9.1 in.).

Figure 6 is an exploded view of tensile portion of the interaction diagram. It is seen that all the load combination points are inside the curve, and the design requirements are satisfied.

Computer output for the design of interior panels and overhang portion of concrete deck slab are shown in Figures 7 and 8.

\section{Significance of Design Variables}

Several deck overhangs with different geometries were designed to observe the significance of each design variable.

9.1. Load Combinations. It is important that the extreme event load case with transverse crash force transfers a constant bending moment and tensile force along the entire length of deck overhang. This is unlike the effect of wheel live load which produces variable moment (zero to maximum). It is seen in Figures 3 or 4 if the first and second load cases (which are almost flat) are compared with third and fourth cases (which are approx. linear). For this reason, the conventional common practice to use variable (haunch) overhang thickness will not help if one of the first two cases is governing the design. It was observed that the first two extreme event load combinations will govern the overhang 


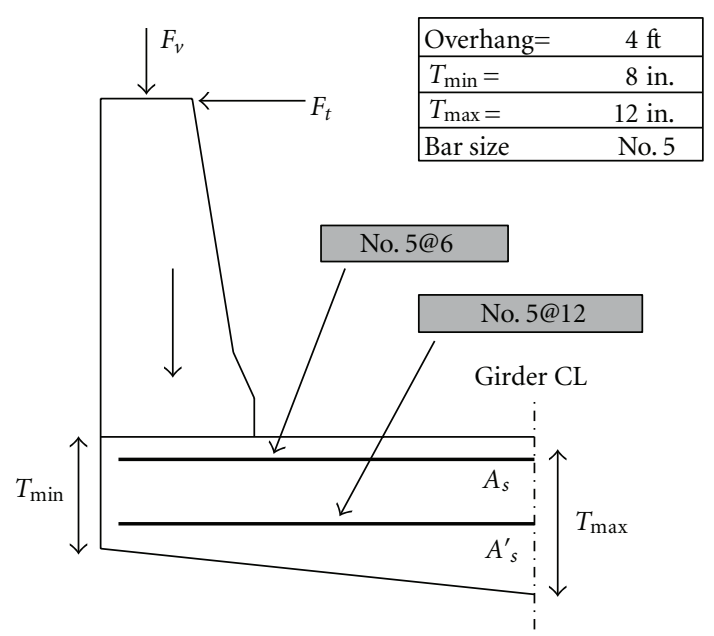

FIGURE 8: Deck overhang LRFD design output for a girder-slab bridge.

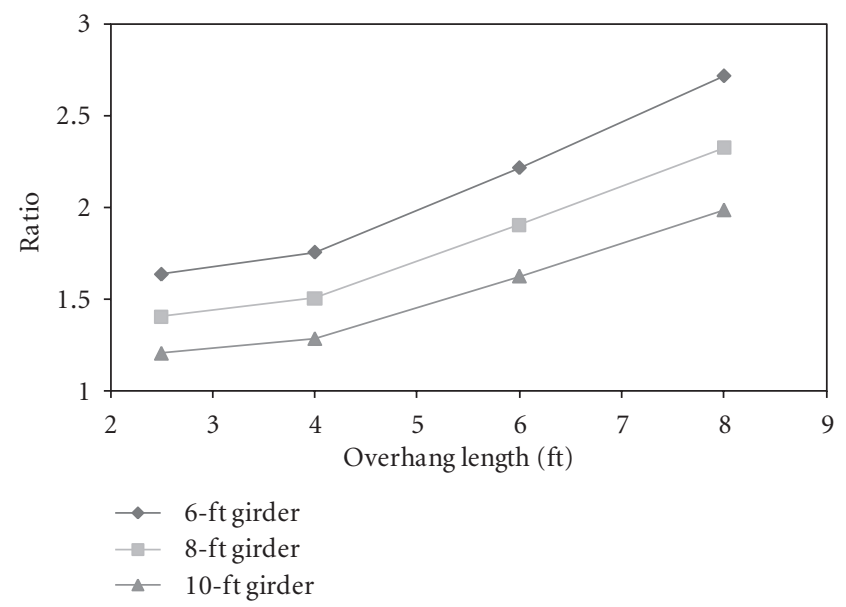

FIgURE 9: Significance of overhang top bars.

design up to lengths of $5 \mathrm{ft}$ and $6.5 \mathrm{ft}$ for test levels of TL4 and TL-5, respectively. These lengths are probably the maximum practical limits. If a variable thickness is used, the deck section and reinforcements at the barrier location must be used for design. Deck overhang section at a point under the interior face of barrier was used in this program.

9.2. Barrier Ends or Joints. The ends or joint locations create a more critical failure in the barrier (and hence the deck) compared to continuous points. Compare joint and continuous cases (the first two load combinations) in Figures 2 and 3. At joints or barrier ends, the crash bending moment is about $60 \%$ to $75 \%$ higher than continuous locations. The barrier and deck overhang should be designed properly at these points.

9.3. Significance of Overhang Reinforcement. A comparison was performed between required overhang top reinforcement with the adjacent interior panel top bars, and Figure 9 shows the ratio of required overhang to interior panels'

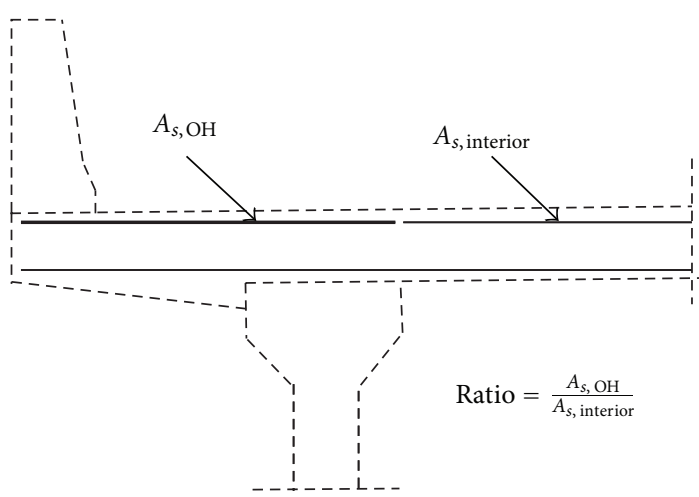

FIGURE 10: Overhang and interior top bar comparison.

top reinforcement. The vertical axis shows the ratio (see Figure 10) of top bars of overhang to top bars of adjacent interior panel. It was shown that this ratio will significantly increase with overhang length.

9.4. Overhang Design. Direct manual design of reinforced concrete section under combined tension and bending seems to be time consuming and tedious. Numerous examples were solved with this automated computer method. It was observed that, for overhang length limits mentioned before, a simplified manual design can be established as follows.

(i) The top bars in the overhang may be designed based on maximum bending moment (and ignoring the associated tensile force) among the four load combinations (most of the time the first or second case, the extreme event for $F_{t}$ is critical). For simplicity, the effect of bottom bars can be ignored in this process. In case of variable (haunch) thickness, the design should be based on the deck section properties at the location of barrier-to-deck connection (which has the least thickness).

(ii) The bottom bars in the overhang may be assumed to be similar to bottom bars of the adjacent interior deck panel. This means that we can simply continue the bottom bars from the interior panel into the overhang.

\section{Conclusion and Suggested Simplified Design Method}

Detailed investigation was performed for the concrete deck slabs by developing a spreadsheet computer program. Different design methods for the interior deck panels were compared. By adopting the empirical design method for $2.74-\mathrm{m}$ (9-ft) girder spacing, the required deck steel reinforcement is about $75 \%$ and $50 \%$ of those given by LFD and LRFD traditional methods, respectively. Because of the significant difference, most of the designers probably hesitate to use the LRFD empirical method.

For barrier-overhang interaction and their design, NCHRP crash test data were incorporated into the program to check the barrier adequacy. For most practical cases, 
the overhang design is governed by extreme event limit state load data given by crash test results. This requires the concrete section to be designed for combined effect of bending moment and axial tension. The program is capable to construct the axial load and bending moment interaction diagram and check the design adequacy for crash extreme events and strength limit states. A simplified manual design approach was also proposed.

The following shows the simplified design method suggested based on this study. This design method will pass the LRFD crash forces for most practical cases. It was shown that this simplified method is acceptable for overhangs up to $7 \mathrm{ft}$ for a crash level of TL-4.

(1) Design the top bars for Extreme Event crushing moment caused by $F_{t}$ only (ignoring the axial tension).

(2) Provide nominal bottom bars (or continuation of designed adjacent internal panel bottom bars).

\section{References}

[1] AASHTO, Standard Specification for Highway Bridges, AASHTO, Washington, DC, USA, 17th edition, 2002.

[2] AASHTO, AASHTO LRFD Bridge Design Specifications, AASHTO LRFD, Washington, DC, USA, 2008.

[3] A. S. Nowak, "Calibration of LRFD bridge code," ASCE Journal of Structural Engineering, vol. 121, no. 8, pp. 1240-1251, 1995.

[4] H. E. Ross Jr., D. L. Sicking, and R. A. Zimmer, "National Cooperative Highway Research Program (NCHRP), Report 350: Recommended Procedures for the Safety Performance Evaluation of Highway Features," Tech. Rep., Transportation Research Board, National Research Council, Washington, DC, USA, 1993.

[5] E. C. Lohrey, "Three (3)-Year Field Evaluation of the Narrow Connecticut Impact-Attenuation System (NCIAS)," Tech. Rep. 1221-F-94-3, Research Project HPR-1221, 1994.

[6] J. F. Carney III, C. E. Dougan, and E. C. Lohrey, "Summary of the NCHRP Report 350 Crash Test Results for the Connecticut Truck Mounted Attenuator,” Tech. Rep. 2216-1-95-2, 1995.

[7] W. L. Menges and C. E. Buth, "NCHRP Report 350 Testing of the Narrow Connecticut Impact Attenuation System (NCIAS)," Tech. Rep. TTI: 404231-1-6, 1999.

[8] E. Smith, "Summary of the NCHRP Report 350 Crash Test Results for the narrow Connecticut Impact Attenuation System," Tech. Rep. 2216-2-02-5, 2003. 

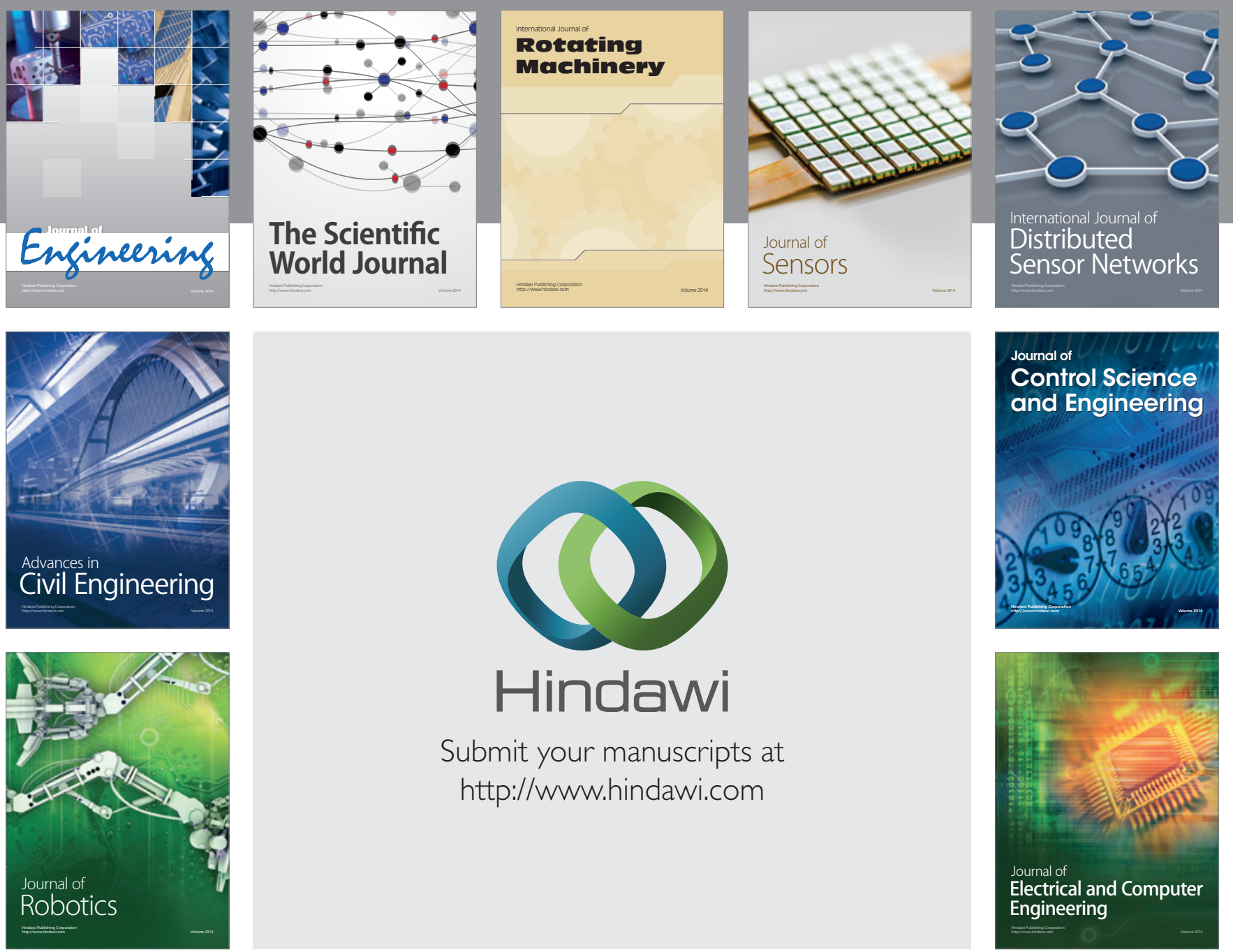

Submit your manuscripts at

http://www.hindawi.com
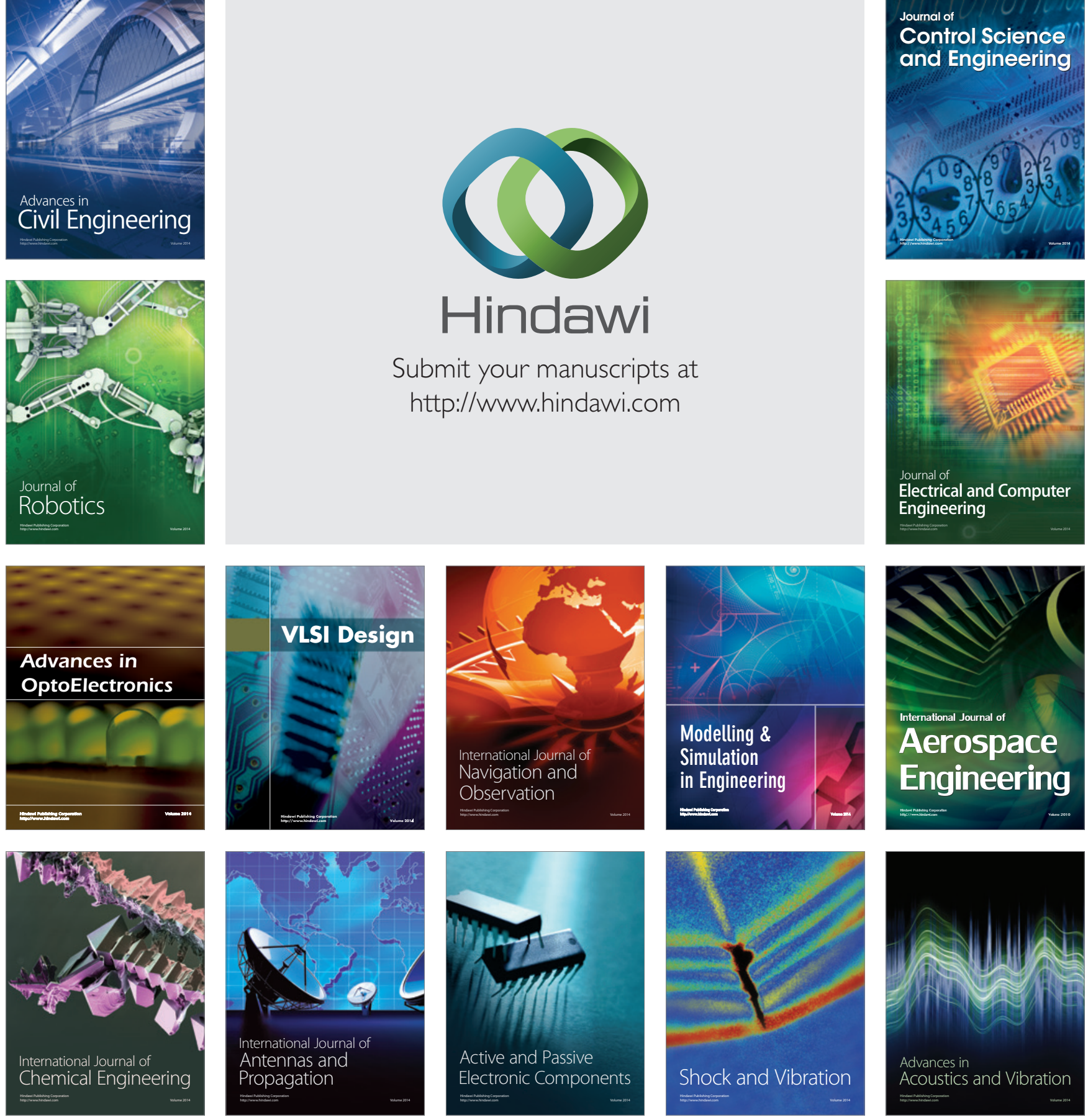